\title{
Kinetic Comparisons of Amniotic Fluid Inactive Renin and Renal Renin Using Synthetic and Human Renin Substrates
}

\author{
Robert C. Franks, ${ }^{*}$ Francis Bodola, ${ }^{*}$ Robert D. Renthal, $\dagger$ \\ AND RoBERT H. HaYashił \\ Departments of *Pediatrics and tBiochemistry, University of Texas Health Science Center, \\ San Antonio, Texas 78284-7806, and $¥$ Department of Obstetrics and Gynecology, \\ University of Michigan Medical School, Ann Arbor, Michigan 48109
}

Received July 22, 1985

There are elevated concentrations of inactive renin during pregnancy in maternal plasma (1-3), in the fetal circulation (4), and in amniotic fluid $(1,3,4)$. Chromatographic differences in the inactive renins isolated from plasma and from amniotic fluid are compatible with a maternal renal source of the former and fetoplacental origin of the latter $(3,5)$. Inactive renin is produced by the placenta $(1,6)$ and may be the source of the amniotic fluid inactive renin, comparable to other placental polypeptides (7); a fetal renal source is an alternate possibility. The role(s) of inactive renin in the respective compartments is currently unknown.

The maternal plasma concentration of renin substrate is also increased in pregnancy (8). Renin substrate is normally present in several component forms (9), and not only total concentration but also proportions of the forms may change during pregnancy (10-13). Similar changes occur during estrogen treatment.

During both pregnancy and estrogen treatment, changes in the reaction of renin with substrate have been suggested which may be related to the differing components $(11,13)$. Unless activated, inactive renin from kidney and plasma does not react with renin substrate (14-16); following activation, however, kinetics similar to those with renin have been noted using renin substrate from adult controls $(15,16)$. Comparable studies with amniotic fluid inactive renin and human renin substrate have not been reported.

Although the function of inactive renin in pregnancy is unknown, renin may have a role in the regulation of uteroplacental blood flow $(17,18)$. To evaluate a role for inactive renin, we have in the current study determined the kinetics of inactive renin isolated from amniotic fluid as reflective of fetoplacental inactive renin, with substratc obtained during estrogen treatment as representative of maternal substrate. Determinations have also been made following separation of the plasma substrate into normal and high molecular weight components and with synthetic tetradecapeptide. The kinetics of renal renin with synthetic tetradecapeptide and plasma substrate and its components have also been measured 
for comparisons to published values and to those determined with amniotic fluid inactive renin.

\section{METHODS AND RESULTS}

Isolation of amniotic fluid inactive renin. Five liters of amniotic fluid, which had been collected, pooled, concentrated, and dialyzed as previously described $(5,19)$, was used for the study. Inactive renin was isolated by chromatography with, respectively, phenylethylamine-agarose (5), octyl CL-Sepharose (19), pepstatin-aminobutyl-agarose (19), and Cibacron blue F3GA (19), with slight modification of the column sizes and flow rates previously described. The columns were each developed stepwise and fractions from the step having the maximum inactive renin to renin ratio were pooled for subsequent chromatography. From the final step, the isolate was lyophilized for subsequent determinations of enzyme kinetics. Lyophilization and reconstitution did not result in loss of total activity or in activation of the inactive renin.

Elution profiles of renin and inactive renin were determined using trypsin for activation of inactive renin and plasma from a nephrectomized ewe for substrate, as previously described (5). The angiotensin I (angio I) formed during incubations was quantitated by RIA and results were expressed as micrograms or nanograms per hour per milliliter. Maximum activation of inactive renin in pooled eluates was determined by incubation with five concentrations $(1-100 \mu \mathrm{g} / \mathrm{ml})$ of trypsin.

Protein was measured by absorbance at $280 \mathrm{~nm}$.

The five liters of amniotic fluid contained $9 \times 10^{6} \mathrm{ng}$ angio $\mathrm{I} / \mathrm{hr}$ of inactive renin with specific activity of $127 \mathrm{ng}$ angio $\mathrm{I} / \mathrm{hr} / \mathrm{mg}$ protein $(\sim 0.00026 \mathrm{GU} \cdot \mathrm{mg})$ and an inactive renin: renin ratio of 15 . The procedure resulted in an ovcrall recovery of inactive renin of $8.4 \%\left(7.377 \times 10^{5} \mathrm{ng}\right.$ angio $\left.\mathrm{I} / \mathrm{hr}\right)$, with specific activity of $80,180 \mathrm{ng}$ angio $\mathrm{I} / \mathrm{hr} / \mathrm{mg}$ protein $(\sim 0.167 \mathrm{GU} \cdot \mathrm{mg})$, i.e., 642 -fold purification. The inactive renin:renin ratio was 26 , representing $\sim 4 \%$ activity in the final isolate prior to activation.

Isolation of plasma renin substrate. Fifty milliliters of plasma was obtained from a normotensive woman receiving oral contraceptive pills. Ten milliliters was used for recovery of pooled renin substrate. The remaining $40 \mathrm{ml}$ was used for isolation and further purification of high molecular weight (HMW) and normal molecular weight (NMW) components.

Phenylethylamine-agarose chromatography was used for separation of pooled renin substrate (recovery, 84\%) from plasma renin and inactive renin, as previously described (5). The pooled fractions were dialyzed and lyophilized for use in kinetic determinations.

For the isolation of HMW and NMW renin substrate, the remaining $40 \mathrm{ml}$ of plasma was dialyzed and 10-ml fractions were each applied to four columns of Sephacryl S-200, as previously described (12). The fractions containing HMW substrate, which were free of renin and inactive renin, were pooled, dialyzed, and lyophilized for use in kinetic determinations. The fractions containing NMW substrate, renin, and inactive renin were further chromatographed on phenylethylamine-agarose, as above, for separation of substrate from renin and inactive 
renin, prior to lyophilization. Analysis of the respective pools revealed $7 \%$ of the recovered substrate was HMW and 93\% was NMW.

Enzyme-substrate kinetic studies. The studies were performed with aliquots from a single ampoule of standard human renal renin (68/356, Division of Biologic Standards, London) and with aliquots from a single isolate of amniotic fluid inactive renin, studied before and after activation with trypsin.

Five concentrations of each of four substrates were used for the incubations: synthetic tetradecapeptide $(3.5-56 \mu \mathrm{M})(20)$, pooled plasma renin substrate $(0.08-$ $2.553 \mu \mathrm{M})$, NMW substrate $(0.055-1.765 \mu \mathrm{M})$, and HMW substrate $(0.0174-0.557$ $\mu \mathrm{M})$. A $K_{m}$ was calculated from duplicate reaction progress curves at the five concentrations, using nonlinear regression fits of the Michaelis-Menten equation (21). Three $K_{m}$ determinations were made for each substrate and the mean $\pm \mathrm{SE}$ value for $K_{m}$ calculated. The mean values for $K_{m}$ were compared using Student's $t$ test.

Shown in Table 1 are the results (means $\pm S E$ ) of the kinetic studies using standard renal renin, amniotic fluid inactive renin, and activated amniotic fluid inactive renin with the synthetic and plasma substrates.

Shown in Table 2 are statistical comparisons of the results from Table 1 for plasma substrates. For statistical comparison, $P$ values $\leqq 0.01$ were considered to represent significant differences. (With synthetic tetradecapeptide, the values of $K_{m}$ for standard renal renin, inactive renin, and activated inactive renin were not significantly different.)

Comparisons using values for $K_{m}$ of renin, inactive renin, and activated inactive renin with pooled, NMW, and HMW plasma renin substrate are shown in the upper portion of Table 2. The values for $K_{m}$ of renin with the three plasma substrates were not different. With inactive renin, the values were significantly smaller with pooled $(P<0.01)$ and HMW $(P<0.001)$ substrates when compared to the NMW form. Using activated inactive renin, the $K_{m}$ with HMW was significantly smaller than that for pooled $(P<0.01)$ and NMW $(P<0.005)$ substrates.

In the lower portion of Table 2, statistical comparisons of the plasma substrates with the respective renins are summarized. Using pooled substrate, the $K_{m}$ for

TABLE 1

Values $(\mu \mathrm{M})$ for $K_{m}$ and $V_{\max }$ (Means \pm SE) Using Renal Renin Standard and Amniotic Fluid Inactive Renin before and after Activation with Synthetic Tetradecapeptide (IDP) and Human Plasma Renin Substrates

\begin{tabular}{|c|c|c|c|c|c|}
\hline & & \multirow{2}{*}{$\begin{array}{l}\text { Synthetic } \\
\text { TDP }\end{array}$} & \multicolumn{3}{|c|}{ Plasma } \\
\hline & & & Pooled & NMW & HMW \\
\hline $\begin{array}{l}\text { Renal renin } \\
\text { (standard) }\end{array}$ & $\begin{array}{l}K_{m} \\
V_{\max }\end{array}$ & $\begin{aligned} 31.4 & \pm 1.2 \\
1.9 & \pm 0.06\end{aligned}$ & $\begin{aligned} 0.85 & \pm 0.2 \\
0.3 & \pm 0.05\end{aligned}$ & $\begin{array}{l}1.6 \pm 0.2 \\
0.2 \pm 0.02\end{array}$ & $\begin{aligned} 1.2 & \pm 0.2 \\
0.05 & \pm 0.01\end{aligned}$ \\
\hline Inactive renin & $\begin{array}{l}K_{m} \\
V_{\max }\end{array}$ & $\begin{array}{l}24.8 \pm 2.5 \\
15.8 \pm 1.5\end{array}$ & $\begin{array}{l}1.3 \pm 0.3 \\
1.4 \pm 0.2\end{array}$ & $\begin{array}{l}2.3 \pm 0.2 \\
3.1 \pm 0.3\end{array}$ & $\begin{array}{l}0.5 \pm 0.05 \\
0.3 \pm 0.02\end{array}$ \\
\hline $\begin{array}{l}\text { Inactive renin } \\
\text { (activated) }\end{array}$ & $\begin{array}{l}K_{m}^{\max } \\
V_{\max }\end{array}$ & $\begin{aligned} 34.3 & \pm 2.8 \\
175.5 & \pm 11.4\end{aligned}$ & $\begin{array}{r}2.4 \pm 0.4 \\
25.4 \pm 3.5\end{array}$ & $\begin{aligned} 5.0 & \pm 1.0 \\
83.7 & \pm 15.8\end{aligned}$ & $\begin{array}{l}1.0 \pm 0.2 \\
2.0 \pm 0.2\end{array}$ \\
\hline
\end{tabular}


TABLE 2

Statistical Comparisons of Values for $K_{m}$ from Table 1 for Renal Renin and Amniotic Fluid Inactive Renin before and after Activation with Pooled, NMW, and HMW Plasma Renin Substrates

\begin{tabular}{lccc}
\hline & Pooled vs NMW & Pooled vs HMW & NMW vs HMW \\
\hline Renin & $P>0.01$ & $P>0.05$ & $P>0.05$ \\
Inactive renin & $P<\mathbf{0 . 0 1}$ & $P>0.01$ & $P<\mathbf{0 . 0 0 1}$ \\
Inactive renin $^{a}$ & $P>0.01$ & $P<0.01$ & $P<\mathbf{0 . 0 0 5}$ \\
& Renin vs IR & Renin vs IR & IR vs IR $^{a}$ \\
\hline Pooled substrate & $P>\mathbf{0 . 0 5}$ & $P<\mathbf{0 . 0 0 5}$ & $P>0.01$ \\
NMW substrate & $P>\mathbf{0 . 0 1}$ & $\boldsymbol{P}<\mathbf{0 . 0 0 5}$ & $P>0.01$ \\
HMW substrate & $P<\mathbf{0 . 0 0 5}$ & $P>\mathbf{0 . 2}$ & $P>0.01$ \\
\hline
\end{tabular}

Note. Significant differences $(P \leqslant 0.01)$ are in boldface.

a After activation.

renin was smaller than that for activated inactive renin $(P<0.005)$ but not for unactivated inactive renin. With NMW substrate, the value for renin was significantly smaller $(P<0.005)$ than with activated inactive renin. With the HMW form, the $K_{m}$ for inactive renin was smaller than for standard renin $(P<0.005)$.

\section{DISCUSSION}

Amniotic fluid inactive renin. In the current study inactive renin has been isolated from amniotic fluid following column chromatography on phenylethylamineagarose, octyl-Sepharose, pepstatin-aminobutyl-agarose, and Cibacron blue F3GA. We have previously noted differing behavior on phenylethylamine-agarose of inactive renin from amniotic fluid and from plasma (5); the further chromatographic behavior in this study of amniotic fluid inactive renin was similar to that previously reported for plasma and renal inactive renin (14-16). The final isolate was purified $\sim 642$-fold. In contrast to the completely inactive renin described in kidney and plasma, however, it had an activity of $\sim 4 \%$ the amount measured after activation and we have been unable to isolate a completely inactive form. The observation is similar to that made with inactive renin recovered from cell cultures of chorion in which $\sim 4-5 \%$ of total activity was present before activation (6) and suggests that the inactive renin isolated from amniotic fluid by the procedure used here may originate in chorion. Although there is a single renin gene in humans, the observed differences in activity of renal and chorionic inactive renins might result from post-translational events, as previously suggested (22).

Plasma renin substrate. In this study, renin substrate in plasma from an estrogentreated woman consisted of $93 \% \mathrm{NMW}$ and $7 \% \mathrm{HMW}$. The proportions of the respective forms are generally comparable to those reported by others for plasma obtained during normotensive pregnancy or estrogen treatment (12).

Enzyme-substrate kinetics. The kinetics of standard renal renin with synthetic and plasma substrates were measured in the current study as a basis for comparison to published values. The values for $K_{m}$ were generally comparable to those 
previously reported for renin with synthetic tetradecapeptide (20), for renin with plasma substrate from estrogen-treated subjects (23), and for renin and activated renal-plasma inactive renin with plasma substrate from adult volunteers $(15,16)$.

An association of both pregnancy-induced and estrogen-induced hypertension with the quantity of HMW form of renin substrate has been reported $(12,13)$ and an increased affinity of renin for the HMW substrate suggested (13). In the current study, however, the $K_{m}$ of renin with pooled, NMW, and HMW substrate was not different. The results therefore suggest that if HMW substrate is causally related to hypertension, it is via a mechanism other than altered affinity for renin.

Kinetic studies of amniotic fluid inactive renin have previously been performed with heterologous and not with either synthetic or human substrates (1, 24-26), and results have not been compared to studies with renal renin. In this study, values for $K_{m}$ of inactive renin, both before and after activation, were similar to the value for renal renin standard with synthetic tetradecapeptide.

Using plasma renin substrates, the $K_{m}$ for amniotic fluid inactive renin was significantly smaller $(P<0.01)$ with pooled than with NMW substrate, a difference which could be accounted for by the smaller $K_{m}(P<0.001)$ with HMW vs NMW substrate. Although the kinetics of unactivated inactive renin with pooled and NMW substrate were not significantly different from those of renal renin, the $K_{m}$ of inactive renin with HMW substrate was significantly smaller $(P<$ $0.005)$ than that of renin. Following activation of inactive renin, the values for $K_{m}$ with both the pooled and NMW substrate were significantly larger $(P<0.005)$ than the respective values for renin, while that with HMW substrate was not different.

The current study identifies significant differences between the characteristics previously reported for plasma and renal inactive renin and those observed here with amniotic fluid inactive renin. The presence of activity prior to activation contrasts the amniotic fluid isolate to the "completely inactive" renin from kidney and plasma. The unactivated amniotic fluid inactive renin has kinetic constants with homologous pooled renin substrate comparable to those reported for renalplasma renin and activated renal-plasma inactive renin. It is noteworthy, however, that although the affinity of renin for pooled, NMW, and HMW plasma renin substrates was not different, amniotic fluid inactive renin manifests a small but statistically significant $(P<0.001)$ increase in affinity for the HMW component; the affinity is also significantly greater $(P<0.005)$ than that of renin for HMW substrate.

Collectively, the results of the current study can be interpreted as compatible with a role, as yet undefined, for fetoplacental inactive renin in renin-angiotensin mediated homeostasis of pregnancy. In view of the previously noted association of HMW substrate with pregnancy-induced hypertension and the kinetics reported herein with fetoplacental inactive renin, a further role in the pathogenesis of hypertensive pregnancy may be possible.

\section{SUMMARY}

Inactive renin has been isolated from pooled amniotic fluid and purified $\sim 642-$ fold. Prior to activation the isolates had $\sim 4 \%$ of the activity found after activation. 
The observation is similar to that reported for inactive renin from chorionic cell culture and suggests a placental origin of amniotic fluid inactive renin.

Using plasma from an estrogen-treated woman, renin substrate was recovered free of renin and inactive renin and a portion was separated into NMW and HMW components. The NMW form constituted $\sim 93 \%$ and the HMW form $\sim 7 \%$ of the renin substrate.

Amniotic fluid inactive renin was used for determinations of enzyme-substrate kinetics with the pooled, NMW, and HMW plasma substrate and tetradecapeptide synthetic substrate, and the results were compared to similar determinations using standard renal renin. Using synthetic substrate, the kinetics of renal renin and amniotic fluid inactive renin before and after activation were similar. The kinetics of renal renin with pooled, NMW, and HMW plasma substrate were also similar.

Amniotic fluid inactive renin had a lower $K_{m}$ with pooled than with NMW substrate, however, which resulted from a significantly smaller $K_{m}$ with HMW component. Although the affinity constants with pooled substrate were not different for renin and inactive renin, the $K_{m}$ of inactive renin was significantly less with the HMW component of plasma renin substrate.

The observations are compatible with a role for placental inactive renin in normal pregnancy and suggest the possibility of a further role in hypertensive pregnancy.

\section{ACKNOWLEDGMENT}

This study was supported by Research Grant HL-27505 from the National Institutes of Health.

\section{REFERENCES}

1. Shulkes, A. A., Gibson, R. R., and Skinner, S. L., Clin. Sci. Mol. Med. 55, 41 (1978).

2. Sealey, J. E., Wilson, M., and Morganti, A. A., Clin. Exp. Hypertens. Part A 4, 2373 (1982).

3. Hseuh, W. A., Luetscher, J. A., Carlson, E. J., Grislis, G., Fraze, E., and McHargue, A., J. Clin. Endocrinol. Metab. 54, 1010 (1982).

4. Franks, R. C., and Hayashi, R. H., Amer. J. Obstet. Gynecol. 134, 20 (1979).

5. Franks, R. C., Bodola, F., Renthal, R. D., and Hayashi, R. H., Gynecol. Obstet. Invest. 20, 14 (1985).

6. Acker, G. M., Galen, F. X., Devaux, C., Foote, S., Papernix, E., Pesty, A., Menard, J., and Corvol, P., J. Clin. Endocrinol. Metab. 55, 902 (1982).

7. Belisle, S., and Tulchinsky, D., in "Maternal-Fetal Endocrinology" (D. Tulchinsky and K. J Ryan, Eds.), p. 169. Saunders, Philadelphia, 1980.

8. Wilson, M., Morganti, A. A., Zervoudakis, I., Letcher, R. L., Romney, B. M., Von Oeyon, P., Papera, S., Sealey, J. E., and Laragh, J. H., Amer. J. Med. 68, 97 (1980).

9. Eggena, P., Hidaka, H., Barrett, J. D., and Sambhi, M. P., J. Clin. Invest. 62, 367 (1978).

10. Gordon, D. B., and Sachin, I. N., Proc. Soc. Exp. Biol. Med. 156, 461 (1977).

11. Hidaka, H., Itoh, T., Sato, R., and Oda, T., Japan. Circ. J. 44, 375 (1980).

12. Tewksbury, D. A., and Dart, R. A., Hypertension 4, 729 (1982).

13. Shioniri, H., Eggena, P., Barrett, J. D., Thananopavarn, C., Golub, M. S., Eggena, Z., Nakamura, R., Judd, H. L., and Sambhi, M. P., Biochem. Med. 29, 14 (1983).

14. Chang, J.-J., Kisaragi, M., Okamoto, H., and Inagami, T., Hypertension 3, 509 (1981).

15. Atlas, S. A., Sealey, J. E., Hesson, T. E., Kaplan, A. P., Menard, J., Corvol, P., and Laragh, J. H., Hypertension 4 (Suppl. II), 86 (1982).

16. Hseuh, W. A., Carlson, E. J., and Dzau, V. J., J. Clin. Invest. 71, 506 (1983).

17. Hseuh, W. A., Salatinjants, A., and Carlson, E. J., Clin. Res. 32, 266A (1984). 
18. Wilkes, B. M., Krim, E., and Mento, P. F., Clin. Res. 33, 317A (1985).

19. Franks, R., Bodola, F., Renthal, R. D., and Hayashi, R. H., Clin. Sci. 64, 481 (1983).

20. Burton, J., Poulsen, E., and Haber, E., Biochemistry 14, 3892 (1975).

21. Roberts, D. V., in "Enzyme Kinetics in Cambridge Chemistry Texts" (D. T. Elmore, A. J. Leadbetter, and K. Schofield, Eds.), p. 300. Cambridge Univ. Press, New York, 1977.

22. Soubrier, F., Panthier, J.-J., Corvol, P., and Rougeon, F., Nucleic Acids Res. 11, 7181 (1983).

23. McDonald, W. J., Cohen, E. L., Lucas, C. P., and Conn, J. W., J. Clin. Endocrinol. Metab. 45, 1297 (1977).

24. Morris, B. J., Biochim. Biophys. Acta 527, 86 (1978).

25. Ito, T., Devaux, C., Gautray, J. P., Menard, J., and Corvol, P., Biochim. Biophys. Acta 569, 202 (1979).

26. Johnson, R. L., Fleming, N. W., and Poisner, A. M., Biochem. Pharmacol. 28, 2597 (1979). 